\title{
Application of Negative Binomial Regression for Assessing Public Awareness of the Health Effects of Nicotine and Cigarettes
}

\author{
Temesgen Zewotir ${ }^{2}$ and Shaun Ramroop \\ School of Statistics and Actuarial Science, \\ University of KwaZulu-Natal
}

\section{ABSTRACT}

Both the public and private sectors have acted responsibly to help decrease smoking-related deaths by putting health warnings on all cigarette packages. This study investigated the social or demographic factors associated with public awareness of health warnings on the harmful effects of environmental tobacco smoke based on baseline data collected by the South African Human Sciences Research Council (HSRC). Respondents in the survey were asked to recall the number of anti-smoking messages which appeared as warning messages on cigarette advertisements. The number of anti-smoking messages recalled ranged from 0 to 9 with a mean of 3.09 (variance of 5.99) and a median of 3.00. Because the variance was nearly two times greater than the mean, the negative binomial regression model provided an improved fit to the data and accounted better for overdispersion than the Poisson regression model, which assumed that the mean and variance are the same. The level of education and race were found to be the most significant factors. Moreover, the lower socio-economic class nonsmokers' anti-smoking messages recalling rate was 2.5 times that of the lower socio-economic class smokers. Unlike men, women's anti-smoking message response rate increased with income.

2 Please direct all correspondence to Temesgen Zewotir, School of Statistics and Actuarial Science, University of KwaZulu-Natal, Private Bag X01, Scottsville, 3209; E-mail: Zewotirt@ukzn.ac.za 


\section{Key words}

environmental tobacco smoke, negative binomial regression, overdispersion, Poisson regression, rate ratios, smoking

\section{Introduction}

Cigarette smoke is a complex mixture of chemicals produced by the burning of tobacco and additives. The smoke contains compounds of different physicochemical natures and degrees of harmfulness. Some of these compounds cause heart and lung diseases, and all of them can be deadly (Brook et al., 2004). The cause distribution of mortality due to smoking in South Africa is similar to that found in developing countries, such as China and India, with the exception of respiratory conditions (Groenewald et al., 2007). In South Africa, chronic obstructive pulmonary disease accounts for a smaller proportion of tobacco-attributable mortality (18\%) than in developing countries (27\%), and other respiratory diseases and respiratory tuberculosis account for a larger proportion (20\% vs $13 \%$ ). In terms of the overall deaths in South Africa, Groenewald et al. (2007) estimated that about $8.5 \%$ of all deaths in 2000 could be attributed to smoking. Accordingly, smoking ranked third (after unsafe sex/ sexually transmitted diseases and high blood pressure) in terms of mortality among 17 risk factors evaluated. Sitas et al. (2004) also estimated that about 8\% of all adult deaths (> $25 \mathrm{yrs}$ ) were caused by smoking in 1998 .

Environmental tobacco smoke, also known as passive smoking or second hand smoke, occurs when non-smokers inhale other people's tobacco smoke. This includes mainstream smoke (i.e. smoke that is inhaled and then exhaled into the air by smokers) and sidestream smoke (i.e. smoke that comes directly from the burning tobacco in cigarettes). Environmental tobacco smoke contains the same harmful chemicals as the smoke that smokers inhale. Recently, the documented adverse effect of tobacco smoke components on so called passive smokers has been very strongly emphasised (Bjørn \& Nielsen, 1996; Hanke et al., 1999; Repace, Kawachi, \& Glantz, 1999; Witorsch, 1998).

There is strong evidence that environmental tobacco smoke causes serious damage to human health. Several epidemiological investigations (see, for example, Bennett et al., 1999; Environmental Protection Agency, 1992; Fontham et al., 1994; Malats et al., 2000; Miller et al., 2003; National Cancer Institute, 2007) have demonstrated that environmental tobacco smoke 
contributes to the following health effects: carcinogenic (lung and nasal sinus cancer), cardiovascular (heart disease mortality, acute and chronic coronary heart disease morbidity), respiratory (in children: acute lower respiratory tract infections, asthma induction and exacerbation, chronic respiratory symptoms, middle ear infections; in adults: eye and nasal irritation), and developmental (foetal growth: low birth weight or small for gestational age, sudden infant death syndrome). The effects associated with environmental tobacco smoking exposure include cervical cancer, exacerbation of cystic fibrosis, decreased pulmonary function, spontaneous abortion and an adverse impact on cognition and behaviour (National Cancer Institute, 2006).

Bearing all this in mind, all possible aspects of passive tobacco smoke as well as actions aimed at reducing related effects have been markedly intensified during recent years. Both the public and private sectors have acted to help decrease smoking-related deaths and illnesses in South Africa. Since 1993, health warnings have been required on all cigarette packages. Parliament banned cigarette advertising on TV and radio in 1999. The Tobacco Control Act of 1993 restricts smoking in certain public places. These regulations range from simple restrictions, such as designated areas in government buildings, to laws that ban smoking in all public places and workplaces. Taxes on cigarettes have risen in recent years to discourage young people from starting to smoke and to encourage smokers to quit (National Cancer Institute, 2007).

Though there has been growing concern by government and non-government organisations about potential adverse health effects related to exposure to environmental tobacco smoke, public awareness is not high when compared to other health problems (like malaria and tuberculosis). Brundtland (2000), the then Director General of the World Health Organization (WHO), noted that by 2030, unless the world takes preventative measures, tobacco will kill more people than malaria, tuberculosis and maternal and childhood conditions combined. Appropriate awareness assessment is crucial, since the health effects of environmental tobacco smoke are likely to be perceived as small in magnitude. Appropriate awareness assessment is also needed for inferring causality and for risk assessment. In addition, exposure assessment is obviously necessary for the development of preventive measures.

The purpose of this study was to assess people's awareness of health warnings regarding the harmful effects of smoking in South Africa. In particular, the researchers investigated which social or demographic groups are more aware 
of government health warnings on the harmful effects of environmental tobacco smoke. Such a study provides a first step to epidemiologists, health-related field specialists and public well-being advocators/organisations for appropriate intervention for a targeted group of people. Such a targeted approach is absolutely essential in a society like South Africa where there is immense socio-demographic disparity.

\section{Materials and Methods}

South African adults' perceptions of the health effects of nicotine and cigarettes were surveyed by means of a series of interviewer-administered questionnaires conducted by fieldworkers of the HSRC through omnibus surveys in October 1996. This survey was conducted after the implementation of the Tobacco Control Act of 1993. The population was stratified by type of area within Gauteng. The sample allocation to the resulting strata was done proportionally to the 1991 census figures. Multistage cluster sampling with probability proportional to size was used to draw respondents, with the adjusted 1991 population census figures as a measure of size. Census enumeration areas and similar areas were used as the clusters. There were 40 clusters in total in Gauteng. The clusters that constituted the data are considered to be a random selection of clusters from all the clusters in Gauteng. A random selection of respondents was then drawn from the clusters, for example, there were four respondents from cluster 1. All clusters were drawn with a probability proportional to size, whilst households were drawn from the final clusters with equal probability. One respondent aged 18 years or older was selected from each household by applying a grid. For each selected respondent, a sampling weight was calculated, using the stratification variables of province and type of area and by post-stratification for age, gender, education and race. Respondents in the survey were asked to recall a number of anti-smoking messages which appeared as warning messages on cigarette advertisements. The sample size of 343 was chosen by the HSRC surveyors. The surveyed variables were race, sex, marital status, socio-economic status, smoking status, age, awareness of the link of smoking (to cancer, heart disease and lung disease) and education level.

The current data study population consisted of Gauteng residents only. Gauteng is one of the nine provinces in South Africa; it is highly urbanised and considered to be the economic powerhouse of the Southern African region whilst also being home to South Africa's largest cities, namely, Johannesburg and Pretoria. Using a census enumeration frame, a random sample of 343 
respondents was drawn. Respondents in the survey were asked to recall the number of anti-smoking messages which appeared as warning messages on cigarette advertisements. There were at least nine different warning messages on South African cigarette packages, and advertisements shown on radio and television, and in cinemas, newspapers, magazines, billboards, posters in shops and pamphlets. The most common warning messages were: (a) Danger: Smoking can kill you; (b) Danger: Smoking causes cancer; (c) Smoking damages your lungs; (d). Warning: Don't smoke near children; (e) Pregnant? Breast feeding? Your smoking can harm your baby; (f) Danger: Smoking causes heart disease; (g) Tobacco is addictive; (h) Your smoking can harm those around you; and (i) Tobacco causes cancer.

Only people who were 18 years or older were included in the study. For each respondent the total number of messages spontaneously recalled was noted. The socio-demographic variables categories were encoded as race (black, coloured, Indian and white), sex (male and female), age (<25 yrs, 25-54 yrs and $55+\mathrm{yrs}$ ), socio-economic status (lower class, middle class and upper class), marital status (married or not married), smoking (non-smoker or smoker), and educational level on a 4-point scale (primary, secondary, higher secondary and university). It should also be stated that ex-smokers were categorised as nonsmokers in this survey as the smoking variable only involved the two categories. In other words, the survey only concentrated on respondents' current smoking status.

A generalised linear model (GLM) analysis was carried out to investigate the demographic and socio-economic factors affecting respondents' awareness of health warnings on the harmful effects of smoking. Since the response variable of interest, which is the total number of messages spontaneously recalled, was a count data, it may not be reasonable to assume that the data were normally distributed. As a result the traditional linear model is not applicable. A GLM extends the traditional linear model to a wider range of data analysis problems (normal, inverse Gaussian, gamma, Poisson, binomial) and a function can be used to link the expected response mean and a linear function of the explanatory variables. In short, a GLM can be constructed by choosing an appropriate link function and response probability distribution (McCullagh and Nelder, 1989; Dobson, 2001; Agresti, 2002).

The best known GLMs for count responses assume a Poisson or a negative binomial distribution. The Poisson distribution has a positive mean. Although 
a GLM can model a positive mean using identity link, it is more common to model the log of the mean. The log link is particularly attractive for a Poisson or a negative binomial regression because it ensures that all the predicted values of the response variable will be nonnegative. Detailed discussion about Poisson GLMs can be found in Lindsey (1995) and Agresti (2002). The Poisson regression restricts the response variable to have mean-variance equality. If this assumption is violated, the resulting estimates are consistent, but, estimates of the variance are not. It can result in spuriously small standard errors of the estimates (Barron, 1992). These inconsistent variance estimates invalidate any hypothesis testing.

Either the deviance or Pearson Chi-square divided by the degree of freedom is used to detect overdispersion or underdispersion in the Poisson regression (SAS Institute, 2004). Values greater than 1 indicate overdispersion, that is, the true variance is bigger than the mean, whereas values smaller than 1 indicate underdispersion, that is, the true variance is smaller than the mean. Evidence of underdispersion or overdispersion indicates inadequate fit of the Poisson model. Overdispersion can be tested for with a likelihood ratio test based on the Poisson and negative binomial distributions. This test tests equality of the mean and the variance imposed by the Poisson distribution against the alternative that the variance exceeds the mean (Cameron \& Trivedi, 1998).

The usual method of controlling for overdispersion involves correcting the standard errors and test statistics (Agresti, 2002). Although this adjustment is an improvement over a conventional Poisson regression, the coefficients lack efficiency because they have more sampling variability than is necessary (Allison, 1999). An alternative strategy for analysing count data, which avoids the problems inherent with the Poisson regression overdispersion/ underdispersion, is to fit a negative binomial regression model (Agresti, 2002; Allison, 1999). All the analyses of this study were carried out using the SAS 9.1 .

\section{Results}

\section{Descriptive results}

The sample consisted of $45 \%$ men and $55 \%$ women. The respondents ranged in age from 18 to over 55 years. Most of them were married (63\%). The highest attained level of education was university (24\%). The lowest level of education 
was primary level education (12\%). In terms of race, the respondents were $46 \%$ blacks, $43 \%$ whites, $7 \%$ Indians and $4 \%$ coloured. About $32 \%$ of the respondents were active smokers; and the remaining $68 \%$ were non-smokers. In terms of socio-economic status, $59 \%$ of the respondents were from higher class and $28 \%$ from middle class. Also the age ranges of the respondents were 18 to $24 \mathrm{yrs}$ (14\%), 24 to 55 yrs (69\%) and over 55 years (17\%).

The number of anti-smoking messages recalled ranged from 0 to 9 with a mean of 3.09 (variance of 5.99), and a median of 3.00. The distribution of the number of messages recalled presented in Figure 1 is skewed to the right. In other words, few respondents recalled five or more messages. The modal number of messages recalled was one message $(22.7 \%)$ followed by three messages (21\%).

Figure 1

Distribution of the number of messages recalled

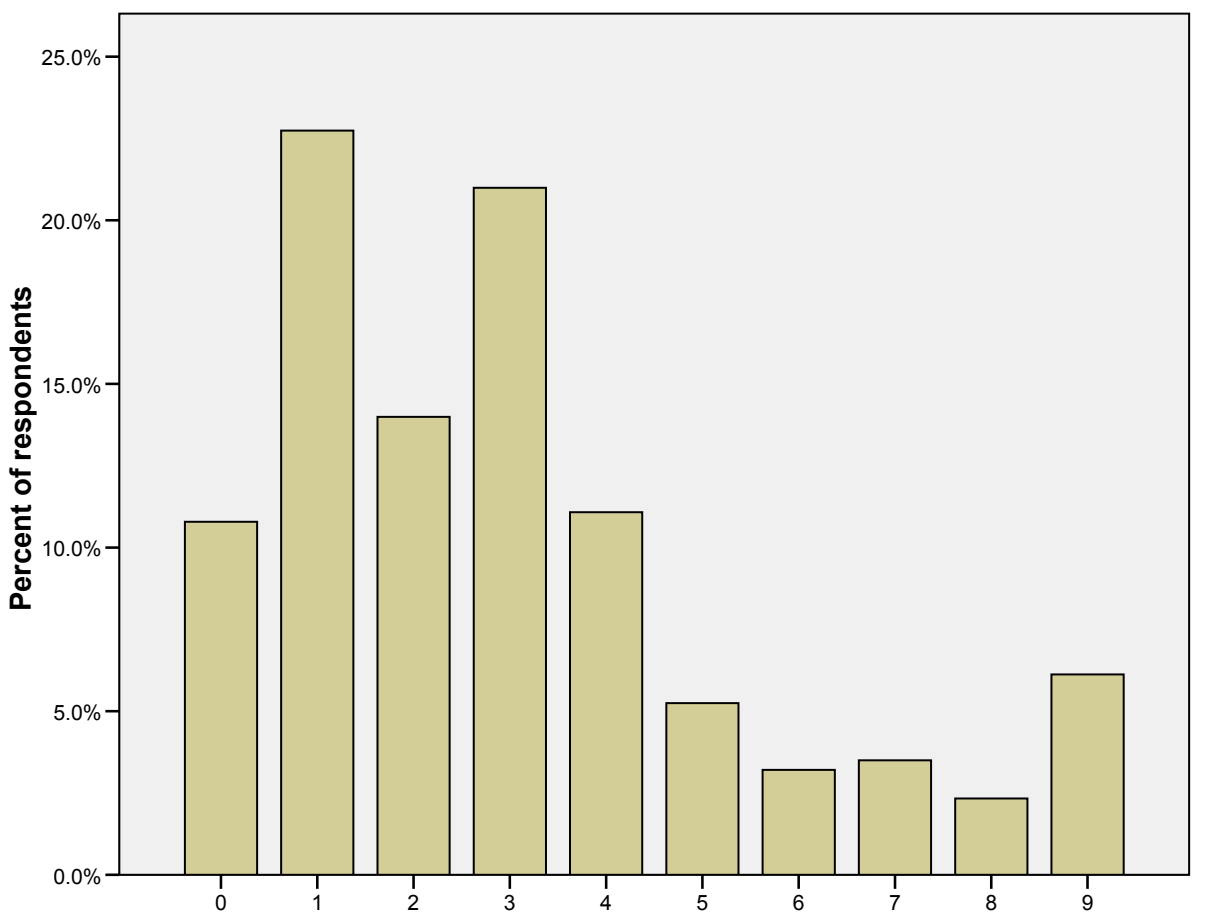


The descriptive results from the survey are presented in Table 1. The results indicate that Indians and blacks have the highest mean number of messages recalled, whilst males have a slightly higher mean number of messages recalled. The younger respondents $(<25 \mathrm{yrs})$ have the higher mean number of messages recalled when compared to the oldest age group ( +55 yrs) who have a lower mean number of messages recalled. The socio-economic group reveals that the lower and higher classes have a close mean number of messages recalled of 3.30 and 3.17. The not currently married group has a higher mean number of messages recalled as compared to the married group. The smoker and nonsmoker groups have an almost equal mean number of messages recalled. An increasing trend in the mean number of messages recalled is seen as the level of education increases from the primary education group to the university education group.

\section{Table 1}

Descriptive results of the of number anti-smoking messages recalled

\begin{tabular}{|l|c|c|c|c|}
\hline & Mean & Median & Mode & $\begin{array}{c}\text { Std } \\
\text { Deviation }\end{array}$ \\
\hline Race & & & & \\
\hline Black & 3.08 & 3.00 & 1.00 & 2.72 \\
\hline Coloured & 1.93 & 1.00 & .00 & 1.91 \\
\hline Indian & 4.17 & 3.00 & 3.00 & 2.73 \\
\hline White & 2.87 & 3.00 & 3.00 & 2.06 \\
\hline Gender & & & & \\
\hline Male & 3.20 & 3.00 & 3.00 & 2.64 \\
\hline Female & 2.87 & 2.00 & 1.00 & 2.27 \\
\hline Age & 3.90 & 3.00 & 2.00 & 2.81 \\
\hline$<25$ yrs & 2.96 & 3.00 & 1.00 & 2.39 \\
\hline 25 yrs-55 yrs & 2.53 & 2.00 & 1.00 & 2.23 \\
\hline+55 yrs & & & & \\
\hline $\begin{array}{l}\text { Socio-economic } \\
\text { status }\end{array}$ & 3.30 & 2.00 & 1.00 & 3.26 \\
\hline Lower class & 2.58 & 2.00 & 1.00 & 2.34 \\
\hline Middle class & 3.17 & 3.00 & 3.00 & 2.27 \\
\hline Higher class & & & & \\
\hline
\end{tabular}




\begin{tabular}{|l|c|c|c|c|}
\hline Marital status & & & & \\
\hline Married & 2.81 & 3.00 & 3.00 & 2.28 \\
\hline $\begin{array}{l}\text { Not currently } \\
\text { married }\end{array}$ & 3.36 & 3.00 & 1.00 & 2.69 \\
\hline Smoking status & & & & \\
\hline Non-smoker & 3.01 & 3.00 & 1.00 & 2.56 \\
\hline Smoker & 3.03 & 3.00 & 1.00 & 2.20 \\
\hline Education & & & & \\
\hline Primary & 2.48 & 1.00 & 1.00 & 2.90 \\
\hline Secondary & 2.54 & 2.00 & 1.00 & 2.24 \\
\hline Higher secondary & 3.19 & 3.00 & 3.00 & 2.36 \\
\hline University & 3.57 & 3.00 & 3.00 & 2.46 \\
\hline
\end{tabular}

\section{Statistical model results}

Turning first to the main effects model, Table 2 shows the results of the Poisson regression fit statistic in explaining the number of anti-smoking messages recalled.

Table 2

Goodness of fit statistic for main effects Poisson and negative binomial regression

\begin{tabular}{|l|l|l|l|}
\hline \multicolumn{1}{|c|}{ Criteria } & \multicolumn{1}{|c|}{ Estimate } & Poisson model & \multicolumn{1}{c|}{$\begin{array}{c}\text { Negative } \\
\text { binomial model }\end{array}$} \\
\hline \multirow{2}{*}{ Deviance } & Value & 622.63 & 377.74 \\
\cline { 2 - 4 } & Df & 329 & 329 \\
\cline { 2 - 4 } & Value/df & 1.89 & 1.15 \\
\hline \multirow{2}{*}{ Pearson Chi-square } & Value & 607.47 & 347.82 \\
\cline { 2 - 4 } & Df & 329 & 329 \\
\cline { 2 - 5 } & Value/df & 1.85 & 1.06 \\
\hline Log-likelihood & value & 143.17 & 174.68 \\
\hline
\end{tabular}

For the Poisson model the Pearson Chi-square values and deviance divided by the degrees of freedom are significantly larger than 1 . But for the negative binomial model, both the Person Chi-square and deviance ratios are sufficiently close to 1 , indicating that the negative binomial model fits the data well, whereas 
the Poisson model does not. The formal test for significance of overdispersion, the log-likelihood ratio, which is $-2 \times$ (log-likelihood of Poisson regression log-likelihood of negative binomial regression), is computed. The log-likelihood ratio becomes 63.03 , which corresponds to a $p$-value $<0.00001$, giving evidence of overdispersion. Evidence of overdispersion indicates inadequate fit of the Poisson model. A common correction is to estimate the event count using negative binomial regression, which is a generalisation of the Poisson model. In the analyses discussed below, the negative binomial specification is used.

It is reasonable to assess the magnitude of the effect of several factors acting jointly over and above their effects considered separately. In other words, the extent to which the effect of one factor changes for different values of one or more other factors needs to be measured, this is called the interactions effect. The significance of the interactions effects were looked at by adding them into the main effects model one at a time and retaining the significant interactions. Accordingly, all the three-way and higher-level interactions effects were obtained non-significant. From the two-way interactions only socio-economic status and smoking, and socio-economic status and sex were significant. The interaction plots were also used to assess the effect a pair of factors has on the response by plotting, for each value of one of the factors, a line between the mean response at the low level of the other factor to the mean response at the high level. An interaction effect is indicated when the lines for different levels of the first factor have unequal slopes. The plots in Figure 2 confirm the presence of interactions socio-economic status and smoking, and socio-economic status and sex. The first plot reveals that for the smoking category the mean number of messages recalled increases as their socio-economic status increases from the lower to the upper class. But for the non-smoker category the mean number of messages recalled decreases as their socio-economic status increases from lower to middle class while the mean number of messages recalled increases as their socio-economic status increases from middle to upper class. The second plot indicates a decrease in the mean number of messages recalled from the males to the females in each of the socio-economic status classes, namely, upper, middle and lower. 
Figure 2

The interaction plots
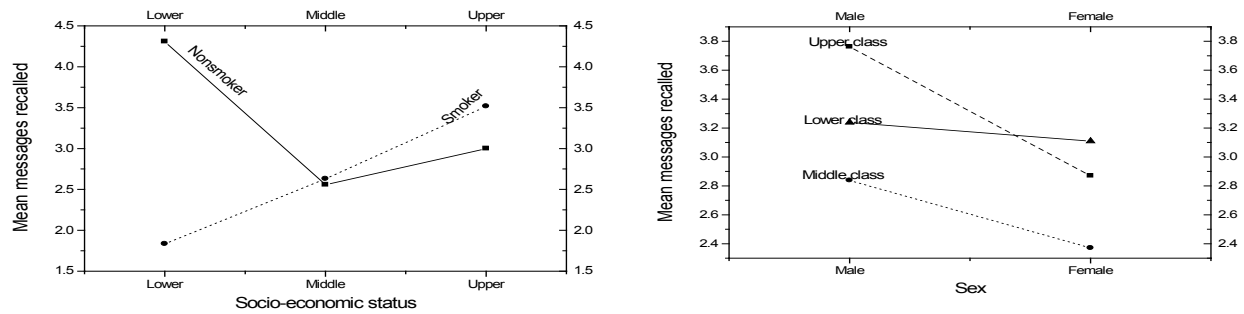

The researchers rechecked if the overdispersion problem in the Poisson regression was eliminated if they used stratified Poison models by smoking status. Accordingly, the log-likelihood ratios $4.03(p=0.045)$ and $55.76(p<$ 0.00001), for smoker and non-smoker strata respectively, favoured the negative binomial regression with interaction instead of the stratified Poisson regression. The results from the negative binomial regression analysis are presented in Table 3 . If the confidence interval includes 1 , then the result is non-significant and can be interpreted as the mean number of anti-smoking messages recalled at the given category equals the mean response at the reference category. 
Table 3

The negative binomial regression estimates of rate ratios with 95\% CIs

\begin{tabular}{|lccc|}
\hline & $\begin{array}{c}\text { Rate Ratios } \\
\text { (RR) }\end{array}$ & 95\% CI \\
\hline Race (Reference = White) & & & \\
Black & $1.32^{*}$ & 1.04 & 1.67 \\
Coloured & 0.89 & 0.55 & 1.44 \\
Indian & $1.47^{*}$ & 1.08 & 2.01 \\
Age (Reference = Over 55 years) & & & \\
< 25 years & 1.36 & 0.98 & 1.89 \\
25 - 55 years & 1.05 & 0.83 & 1.34 \\
Married (Reference = Not married) & & & \\
Married & 0.88 & 0.73 & 1.08 \\
Education (Reference = University) & & & \\
Primary & $0.68^{*}$ & 0.47 & 0.98 \\
Secondary & $0.68^{*}$ & 0.53 & 0.88 \\
Higher secondary & 0.83 & 0.67 & 1.03 \\
Socio-economic status and smoking & & & \\
(Reference = Upper class) & & & \\
Lower-class non-smoker & 1.39 & 0.98 & 1.99 \\
Middle-class non-smoker & 0.83 & 0.61 & 1.12 \\
Lower-class smoker & $0.50^{*}$ & 0.30 & 0.83 \\
Middle-class smoker & 0.72 & 0.48 & 1.07 \\
Socio-economic status and sex & & & \\
(Reference = Upper class) & 0.88 & 0.94 \\
Lower-class man & $0.61^{*}$ & 0.39 \\
Middle-class man & & 0.47 & \\
Lower-class woman & & & \\
Middle-class woman & & & \\
\hline & & & \\
\hline
\end{tabular}

* Significant at $5 \%$ level

When controlling for sex, age, marital status, education and interaction variables, blacks and Indians had the highest anti-smoking messages recalling rate $(\mathrm{RR}=1.32$ and 1.47 respectively) compared with whites. The coloured race groups showed anti-smoking messages recalling rate similar to the whites. 
For a given race, age, socio-economic status, marital status, smoking and marital statuses, the anti-smoking massage recalling rate for the primary and secondary educated people was around two-thirds $(\mathrm{RR}=0.68$ and 0.68 , respectively) of the anti-smoking recalling rate of university level educated people. Generally, the average number of recalled anti-smoking messages increases with level of education.

A highly significant association was found between socio-economic status and smoking $\left(\mathrm{Chi}^{2}=13.17\right.$, $\mathrm{df}=2$ and $\left.p=0.014\right)$. Lower and middle class nonsmokers' anti-smoking awareness rate is similar to non-smoker upper socioeconomic groups. But the lower socio-economic class smokers' anti-smoking message recalling rate is half that of upper socio-economic class smokers. Generally, non-smokers' anti-smoking messages recalling rate is independent to their level of income. But smokers' anti-smoking messages recalling rate increases with an increase in their income.

Men and women's anti-smoking messages recalling rate varies with socioeconomic status. Lower, middle and upper socio-economic class men have a fairly similar recalling rate. But women's anti-smoking message recalling rate increases with income. Men and women's anti-smoking messages recalling rate is associated with their socio-economic status $\left(\mathrm{Chi}^{2}=6.32\right.$, $\mathrm{df}=2$ and $p$ $=0.0424)$. Women's anti-smoking message response rate increases with their income, but men's recalling is stable with the variation of their income. When seen from the other angle, it is found that lower socio-economic class men's recalling rate is 1.79 (with 95\% CI: 1.12-2.85) times the lower socio-economic class women's recalling rate. But for the other two socio-economic classes, men and women did not show a significant difference.

\section{Discussion and Conclusion}

The issue of health warnings related to smoking is an ongoing campaign and its intended effect has been achieved in certain parts of the world. Nevertheless, people's mind sets need to be constantly fashioned via effective communication, and health warnings related to smoking need to be constantly advertised. The above findings show that marital status and age are non-significant factors for anti-smoking awareness. There is a significant difference between the different races with respect to the number of health warning messages recalled $\left(\mathrm{Chi}^{2}=\right.$ 8.81 , df $=3$ and $p=0.0320$ ). Blacks and Indians' warning messages response 
rate is higher than that of whites; coloureds show an anti-smoking messages recalling rate similar to that of whites. This result is perhaps a reflection of the societal acceptance of smoking. Within the black and Indian communities, there is a low social acceptability of smoking. On the other hand, among coloureds and whites, smoking is a fairly accepted personality.

Respondents with a lower level of education are more likely to say they are not at all aware of the harmful effects of smoking. This is not surprising, since almost all smoking warning messages are written messages. The messages are not like the commercial adverts which appeal to most people's eyes. In other words, whilst everyone from those with lower education levels to those with higher education levels is exposed to the dangers of smoking, the written health warning messages on cigarette packages may be overshadowed by the packaging of the cigarette or the acceptability or smoking within the ingroup.

The findings show that smokers' response is associated with their economic status. The lower socio-economic class smokers do not recognise the harmful effects of cigarette smoke as non-smokers do. The lower socio-economic class non-smokers' average number recalled messages is 2.5 times that of the lower socio-economic class smokers ( $R R=2.5$, with $95 \%$ CI $1.47-4.11)$. One possible interpretation of these results is that lower socio-economic class smokers are smoking cigarettes with more ignorance of the danger of smoking than the upper and middle socio-economic class smokers. However, the middle and upper socio-economic class non-smokers' average number recalled messages is similar to the corresponding class smokers $(\mathrm{RR}=1.01$ with $95 \% \mathrm{CI}$ : $0.68-1.50$ and $\mathrm{RR}=0.88$ with $95 \% \mathrm{CI}: 0.70-1.10$ ). Also smokers' anti-smoking messages recalling rate increases with the increase of their income. One possible interpretation of these results is that lower socio-economic class smokers are smoking cigarettes with more ignorance of the danger of smoking than upper and middle socio-economic class smokers. Moreover, smokers from the lower socio-economic class are more likely to be unaware of the harmful effects of smoking than the non-smokers of the same socio-economic group.

Women seem to pay more attention to health hazards associated with smoking and diseases as their economic standards improves. The same trend is observed with smokers. This might show that the health warning messages are not well received (or conceived) by lower socio-economic class smokers and lower socioeconomic class women. 
The other important result reflected in this study is the importance of education for a healthy and well informed society. Given that the South African illiteracy rate is around $24 \%$ of adults over 15 years (6 to 8 million adults are not functionally literate) and the majority of the people are in the lower socioeconomic class, the challenges and future directions of this study are on how to enhance public awareness of the health effects of nicotine and cigarettes to all sectors of the society.

\section{Acknowledgments}

The authors would like to thank Dr Jonathan Levin of the Medical Research Council of South Africa who graciously provided us with the data. They would also like to thank the editor and referees for their comments, which substantially improved this article.

\section{References}

Allison, P. (1999). Logistic regression using the SAS system: Theory and applications. Cary, NC: SAS Institute.

Agresti, A. (2002). Categorical data analysis. New York: Wiley.

Barron, D. (1992). The analysis of count data: Overdispersion and autocorrelation. In V. Peter (Ed.), Sociological methodology. Marsden: Blackwell.

Bennett, W.P, Alavanja, M.C., Blomeke, B., Vahakangas, K.H., Castren K., \& Welsh, J.A. (1999). Environmental tobacco smoke, genetic susceptibility, and risk of lung cancer in neversmoking women. Journal of the National Cancer Institute, 91, 14-2009.

Bjartveit, K., \& Tverdal, A. (2005). Health consequences of smoking 1-4 cigarettes per day. Tobacco Control, 14, 315-320.

Bjørn, E., \& Nielsen, P.V. (1996). Passive smoking in a displacement ventilated room. Indoor Air 1996. Proceedings from: The 7th International Conference on Indoor Air Quality and Climate, July 21-26, Nagoya, Japan, 92-887.

Brook, R.D., Franklin, B., \& Cascio, W. (2004). Air pollution and cardiovascular disease: A statement for healthcare professionals from the Expert Panel on Population and Prevention Science of the American Heart Association. Circulation, 109, 2655-2671.

Brundtland, G.H. (2000). Address at the opening of World No Tobacco Day, World Health Organization. Retrieved June 18, 2007, from http://www.who.int/directorgeneral/ speeches/2000/english/20000531_bangkok.html

Cameron, A.C., \& Trivedi, P.K. (1998). Regression analysis of count data. New York: Cambridge University Press.

Environmental Protection Agency (EPA). (1992). Respiratory health effects of passive smoking: Lung cancer and other disorders. EPA/600/6-90/006F. Retrieved May 4, 2007, from http:// www.epa.gov/iaq/pubs/etsfs.html 
Fienburg, S.E. (1980). The analysis of cross classified data. Cambridge, MA: MIT Press.

Firth, D. (1991). Generalised Linear Models. In D.V. Hinkley, N. Reid \& E.J. Snell (Eds.), Statistical theory and modelling: In honour of Sir David Cox. London: Chapman and Hall.

Fontham, E.T., Correa, P., Reynolds, P., Wu-Williams, A., Buffler, P.A., \& Greenberg, R.S. (1994). Environmental tobacco smoke and lung cancer in nonsmoking women. The Journal of the American Medical Association, 271(22), 1752-1759.

Groenewald, P., Vos, T., Normann, R., Laubscher, R, van Walbeek, C., Saloojee, Y., et al. and the South African Comparative Risk Assessment Collaborating Group. (2007). Estimating the burden of disease attributable to smoking in South Africa in 2000. South African Medical Journal, 97(8), 674-681.

Hammond, S.K. (2002). The efficacy of strategies to reduce environmental tobacco smoke concentrations in homes, workplaces, restaurants and correctional facilities. In H. Levin (Ed.), Proceedings from: The 9th International Conference on Indoor Air Quality and Climate, June 30-July 5, Monterey, California, Santa Cruz.

Hanke, W., Kalinka, J., Florek, E., \& Sobala, W. (1999). Passive smoking and pregnancy outcome in central Poland. Human Experimental Toxicology, 18, 265-271.

Lindsey, J.K. (1995). Modelling frequency and count data. Oxford: Oxford University Press.

Malats, N., Camus-Radon, A.M., Nyberg, F., Ahrens, W., Constantinescu, V., \& Mukeria, A. (2000). Lung cancer risk in nonsmokers and GSTM1 and GSTT1 genetic polymorphism. Cancer Epidemiological Biomarkers Preview, 9, 827-833.

McCullagh, P., \& Nelder, J.A. (1989). Generalised linear models (2nd ed.). London: Chapman and Hall.

McCulloch, C.E., \& Searle, S.R. (2001). Generalized, linear, and mixed models. New York: John Wiley Inc.

Miller, D.P., De Vivo, I., Neuberg, D., Wain, J.C., Lynch, T.J., \& Su, L. (2003). Association between self-reported environmental tobacco smoke exposure and lung cancer: Modification by GSTP1 polymorphism. International Journal of Cancer, 104, 758-763.

National Cancer Institute. (2007). Health effects of exposure to environmental tobacco smoke. Report of the California Environmental Protection Agency. Retrieved May 4, 2007, from http://www.cancercontrol.cancer.gov/tcrb/monographs/10/m10_complete.pdf

Repace, J., Kawachi, I., \& Glantz, S. (1999). Fact sheet on secondhand smoke: The 2nd European Conference on Tobacco or Health, the 1st Iberoamerican Conference on Tobacco or Health, February 23-27, Canary Islands, Spain. Retrieved May 22, 2007, from http://www.repace.com/ SHSFactsheet.pdf

SAS Institute Inc. (2004). SAS/STAT User's Guide (Version 9.1, Chap. 29, Proc GENMOD). Cary (NC): SAS Institute Inc.

Sitas, F., Bradshow, D., Bah, S., \& Peto, R. (2004). Tobacco attributable deaths in South Africa. Tobacco Control, 13, 396-399.

Suh, H.H., Bahadori, T., Vallarino, J., \& Spengler, J.D. (2000). Criteria for air pollutants and toxic air pollutants. Environmental Health Perspectives, 108, 625-633.

Witorsch, P. (1998). Effects of environmental tobacco smoke exposure on pulmonary function and respiratory health in adults: Update 1997. Indoor Build Environment, 7, 4-17. 